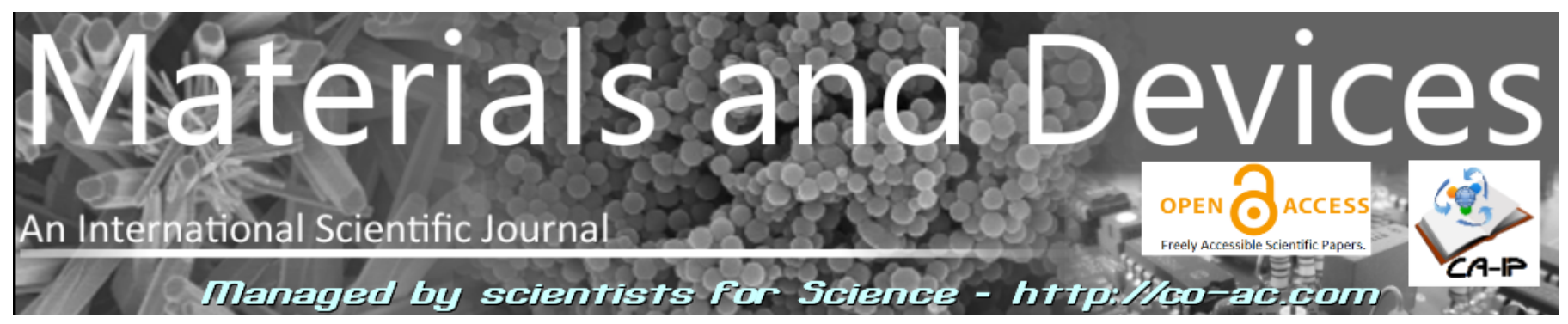

\title{
Graphene-titanate photocatalyst and its use in an air purifying device - prototype demonstration in operational environment
}

\author{
T. Baran (1), S. Wojtyła (1)
}

(1) SajTom Light Future TLD, Wężerów, Poland, e-mail address: biuro@sajtom.pl

Corresponding author : biuro@sajtom.pl

RECEIVED: 23 february 2021. / RECEIVED IN FINAL FORM: 4 march 2021 / ACCEPTED: 12 march 2021

\begin{abstract}
Volatile organic compounds constitute a group of dangerous air pollutants, which can be eliminated by the photocatalytic route. In this work we demonstrated the hydrothermal synthesis of photocatalytic composite CTO-RGO based on copper titanate and reduced graphene oxide. The material is composed of three phases namely rutile, tenorite and reduced graphene oxide, and it shows absorption in a broad range of light (ultraviolet and visible light). CTO-RGO showed an excellent photocatalytic activity in a laboratory scale experiment. Therefore it has been used as an active material in air purifying devices. A prototype was tested in operational environments such as apartment, fitness center and industrial places. Obtained results confirmed the significant decrease of VOC level due to photocatalytic degradation of pollutants.
\end{abstract}

Keywords: PHOTOCATALYSIS, SEMICONDUCTORS, GRAPHENE, TITANATE, NiTiO $3, \mathrm{CUTIO}_{3}, \mathrm{COPPER}$ TITANATE/GRAPHENE OXIDE, VOLATILE ORGANIC COMPOUNDS, AIR PURIFER, AIR POLLUTANTS

\begin{tabular}{l}
\hline Cite this article: T. Baran and S. Wojtyła, OAJ \\
Materials and Devices, Vol 5 \#1, 1203 (2021) - \\
DOI: $10.23647 /$ ca.md20211203 \\
\hline
\end{tabular}

\section{Introduction}

Volatile Organic Compounds (VOCs), polycyclic organic matter, $\mathrm{NO}_{x}, \mathrm{SO}_{2}$ and dioxins are all considered air contaminants that are harmful to humans. ${ }^{[1,2]}$ Air pollution is a major cause of numerous serious disease such as chronic pulmonary diseases, asthma, cancer, cardiovascular diseases, nervous system dysfunctions, depression and cutaneous diseases. Even short time exposition may lead to a headache, nausea, dizziness, malaise, irritation of the eyes and throat.
Volatile organic compounds are a big group of air pollutants, that occur in both, outdoor and indoor air. Concentrations of most VOCs are higher in indoor air than outdoor air. ${ }^{[3,4]}$ The primary emitters of VOCs to indoor air include various consumer and household products, building and construction materials, paints, insulation, smoking, solvents and coating mediums for furniture, and room decorations as well as equipment such as 3D printer. ${ }^{[4,5]}$

VOC pollutants can be eliminated in a photocatalytic way. ${ }^{[6-8]}$ The irradiation of photocatalyst leads to the electron-hole pairs separation and subsequently to the formation of reactive 
oxygen species such as superoxide anion radical, hydroxyl radical, hydrogen peroxide and others. ${ }^{\left[{ }^{9]}\right.}$ These highly reactive molecules oxidize organic compounds (e.g. VOCs) to safe products such as carbon dioxide and water. Moreover reactive oxygen species can inactivate many biological air pollutants such as spore or bacteria. Therefore photocatalysis is considered as a most promising technology towards air purification, while the most efficient photocatalytic materials are: titanium dioxide, metal titanates, zinc oxide, graphitic carbon nitride, tungsten oxide. ${ }^{[7,10-14]}$

Our previous study demonstrated a high photocatalytic activity of titanates (e.g. $\mathrm{NiTiO}_{3}$ and $\mathrm{CuTiO}_{3}$ ) and titanium based materials, in particular towards efficient formation of reactive oxygen species..$^{[9,15]}$ In this paper we show the hydrothermal synthesis of photocatalytic composite based on copper titanate and reduced graphene oxide. Material has been characterized by spectroscopic, crystallographic and microscopy techniques. Photocatalyst shows a promising photocatalytic activity in a laboratory scale experiment. Therefore it has been used as an active material in the air purifying device. The prototype was tested in operational environment such as apartment, fitness center and industrial places.

\section{Experimental}

Preparation of photocatalyst composite copper titanate/graphene oxide (CTO-RGO): for the synthesis of CTO-RGO, reduced graphene oxide (18 mg - purchased from Advanced Graphene Products from Poland) was dispersed in water $(20 \mathrm{~mL})$ and sonicated for $0.5 \mathrm{~h}$ at ambient temperature. Subsequently, $0.436 \mathrm{~g}$ of copper acetace (Sigma Aldrich) was dissolved in $20 \mathrm{~mL}$ of water. The copper solution was poured into RGO suspension. Ethylene glycol (5 $\mathrm{mL}$ ) was added to the mixture. Then, $0.568 \mathrm{~g}$ of titanium(IV) isopropoxide, (98+\%, ACROS Organics) was dissolved in 10 $\mathrm{mL}$ of isopropyl alcohol. Ti-solution was added dropwise into RGO suspension under vigorous stirring condition and stirred for $10 \mathrm{~h}$, and the mixture was then transferred to a Teflon lined autoclave $(\mathrm{V}=150 \mathrm{~mL})$ and heated at $180{ }^{\circ} \mathrm{C}$ for $8 \mathrm{~h}$. The precipitate obtained was separated by centrifugation, washed with water and methanol and dried under vacuum.

Diffuse reflectance spectra (DRS) were measured using a spectrophotometer UV-2600 (Shimadzu) equipped with an integrating sphere (ISR 2600Plus). Photocatalysts were ground with $\mathrm{BaSO}_{4}$ and spectra of formed pellets were measured. Raman spectra were collected using Renishaw instrument. The XRD patterns were measured using a Empyrean X-ray diffraction system (Malvern Panalytical) with a $\mathrm{Cu} K \alpha$ radiation source. Scanning electron microscopy (SEM, Quanta FEG 250 - FEI) was used to characterize the morphology of photocatalyst.

Photocatalytic air purifying devices have been constructed using metal chamber shown in Figure 1. The FFR 200 cassette (Systemair) for circular ducts was used as a chamber of photocatalytic air purifier. The cassette was manufactured from galvanized sheet steel with rubbersealed connections. A circular fan was placed in the entrance of chamber. The chamber was equipped with 5 white LEDs (3,5 mW / ea.). Photocatalyst was deposited onto the inner walls of the glass tube (diameter $150 \mathrm{~mm}$, length $450 \mathrm{~mm}$ ) by a spray coating at ambient temperature, followed by a calcination in $450^{\circ} \mathrm{C}$ for $1 \mathrm{~h}$. The fan and LED were controlled by a Arduino-based driver. Photocatalytic air purifiers were installed in a few different locations (industrial plant, 3D printer lab, apartment, fitness center), as a separate unit, or integrated with air ventilation systems. The cubature of all rooms was not more than $150 \mathrm{~m}^{3}$.

The VOC concentration in air was determined using a gas chromatograph (GC-2030 Naxis, Shimadzu) equipped with FID and TCD detectors as well as a ZB-5 $30 \mathrm{~m}$ capillary column (Zebron). The volume of gas sample was $0,25 \mathrm{~mL}$. The temperature of injector was $180^{\circ} \mathrm{C}$. The initial temperature of column was $70^{\circ} \mathrm{C}$ and then a temperature gradient $\left(15^{\circ} \mathrm{C} / \mathrm{min}\right)$ was applied until $300^{\circ} \mathrm{C}$. Helium was a carrier gas, column flow $1 \mathrm{~mL} / \mathrm{min}$

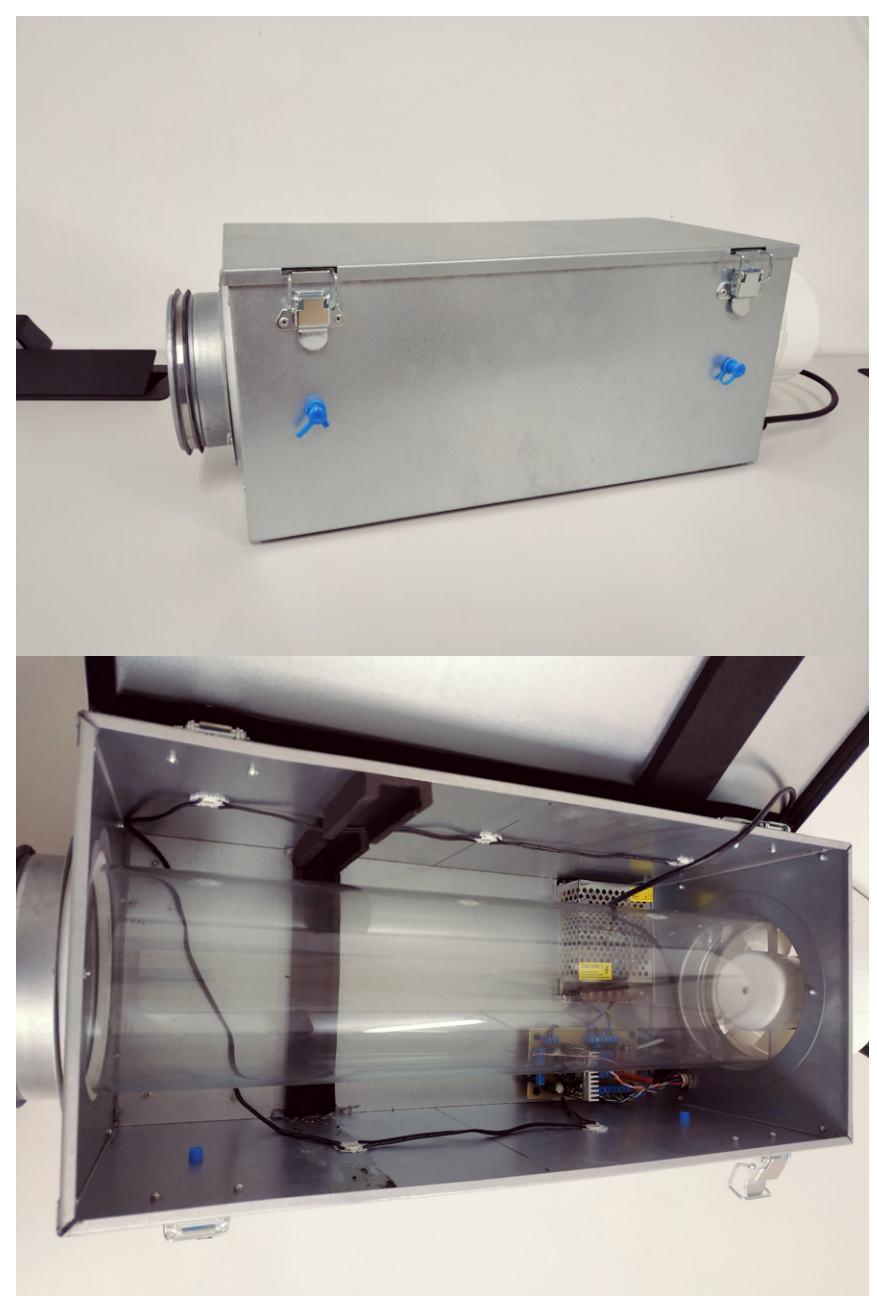

Figure 1: Photocatalytic air purifying devices

\section{Results and discussion}

The hydrothermal synthesis of photocatalytic material results in a 3-phases composite. As determined using XRD analysis the material is composed of rutile phase (titanium oxide), tenorite (copper(II) oxide) and graphene oxide (Figure 2 ). The main peaks of rutile are: $27,6^{\circ}$ ascribed to crystal plane (110); $36,2^{\circ}$ ascribed to plane (101); $41,2^{\circ}$ ascribed to plane (111); $44,0^{\circ}$ ascribed to plane (210); $54,4^{\circ}$ ascribed to plane (211) and 
$56,6^{\circ}$ ascribed to plane (220). Tenorite copper oxide phase shows the following peaks: $32,5^{\circ}$ ascribed to plane (110); $35,3^{\circ}$ ascribed to plane $(002) ; 35,6^{\circ}$ ascribed to plane (11-1); $38,8^{\circ}$ ascribed to plane $(111) ; 48,9^{\circ}$ ascribed to plane $(20-2)$ $53,4^{\circ}$ ascribed to plane (020) and $58,4^{\circ}$ ascribed to plane (202). Reduced graphene oxide is not a well crystallized phase, and it can be observed as a very low intense peak at diffraction angle $26,5^{\circ}$ representing the plane $(002)$.

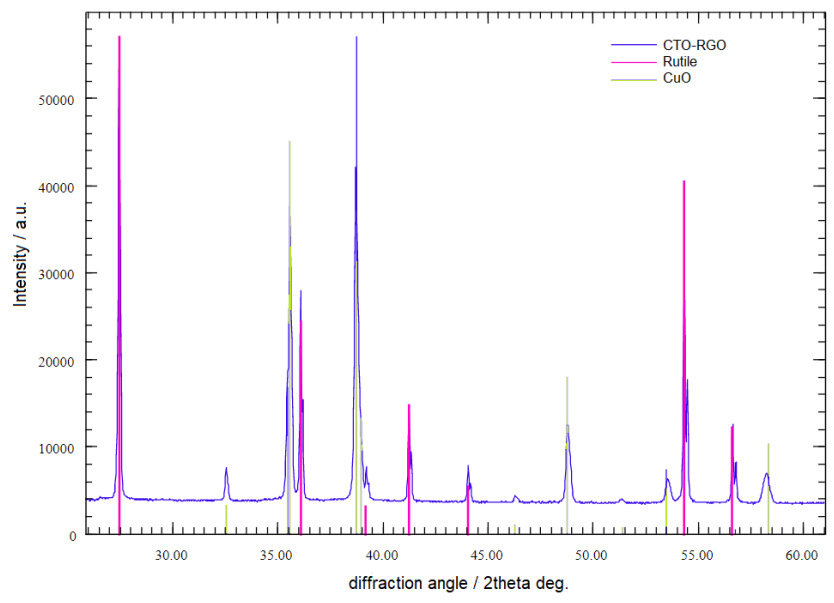

Figure 2: XRD pattern of CTO-RGO

The presence of reduced graphene oxide in the composite was proved by using Raman spectroscopy. The spectrum of CTO-RGO, shown in Figure 3, demonstrates bands at 1329 and $1586 \mathrm{~cm}^{-1}$ that can be assigned to the reduced graphene oxide. ${ }^{[16]}$ Data has been supported by a spectrum of neat RGO material.

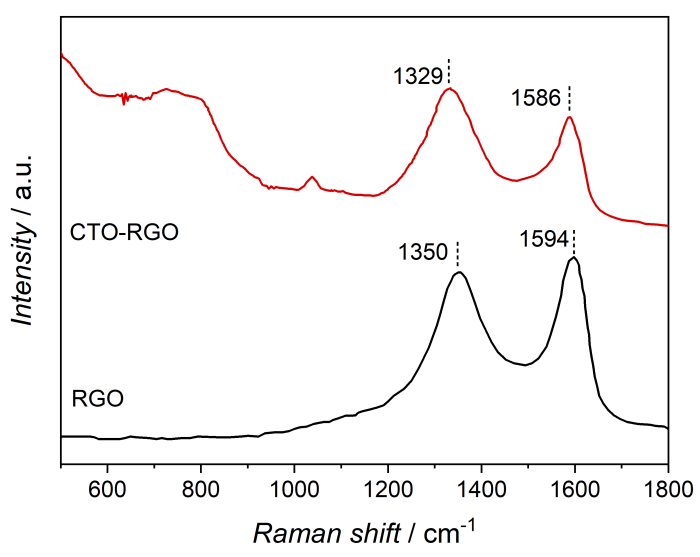

Figure 3: Raman spectra of CTO-RGO and commercial RGO

SEM analysis showed an irregular shape of particles (Figure 4). Smaller particles of diameter ca. 20-50 $\mathrm{nm}$ are aggregated into bigger fractions, of total size up to a few microns.

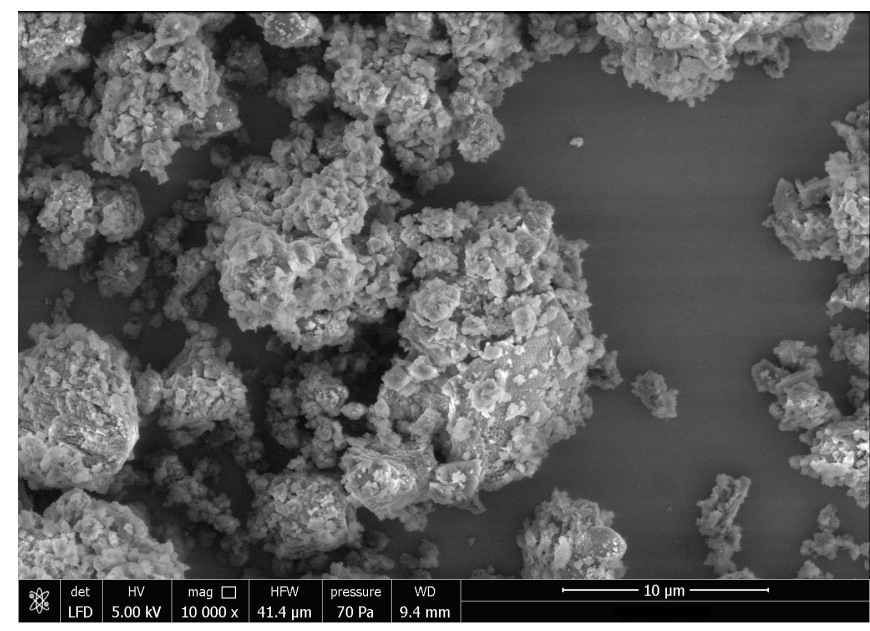

Figure 4: SEM image of CTO-RGO

Optical properties of materials were investigated using diffuse reflectance spectroscopy. The measured reflectance spectra were transformed to the corresponding absorption spectra by applying the Kubelka-Munk function. Both, neat $\mathrm{CuTiO}_{3}$ and CTO-RGO showed a broad range of visible light absorption, as shown in Figure 5. However, the presence of reduced graphene oxide significantly affects the spectrum, in particular for wavelengths higher than $700 \mathrm{~nm}$. Band gap energies of both materials were calculated using Tauc method, considering the material as a semiconductor with direct band gap transition. ${ }^{[17,18]}$ Determined band gap energies are: $1.41 \mathrm{eV}-\mathrm{CuTiO}_{3} ; 1.19$ eV - CTO-RGO. Therefore, it can be concluded that the modification of copper titanate by reduced graphene oxide leads to the levering of band gap energy.
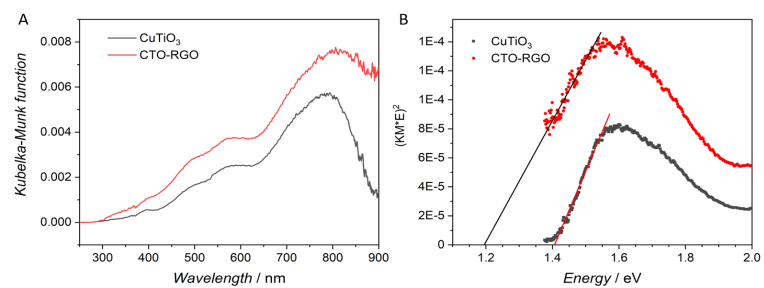

Figure 5: UV-vis spectra of CTO-RGO and neat $\mathrm{CuTiO}_{3}$. A - Kubelka-Munk functions. B - Tauc plots

Photocatalytic activity of composite has been confirmed in two types of experiment: laboratory photocatalytic tests and experiment in operational environment. In a laboratory scale, the photocatalyst has been deposited on a glass plate $(100 \mathrm{~mm}$ $x 100 \mathrm{~mm}$ ) and placed inside a gas-tight glass reactor of total volume ca. $3 \mathrm{~L}$. Photocatalytic film was irradiated using LED $(\lambda=400 \mathrm{~nm})$ in the presence of acetone vapor, as a model VOC air pollution. Concentration of acetone was monitored using GC analysis. As demonstrated in Figure 6, acetone was decomposed within less than 3 hours of irradiation. The test was repeated 3 times to calculate the standard deviation. 


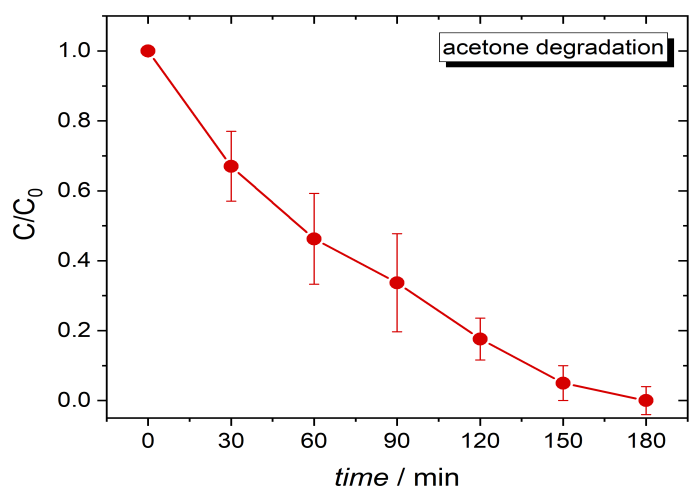

Figure 6: Photocatalytic degradation of acetone in the presence of CTO-RGO. Initial concentration of acetone in gas phase was $\mathbf{3 5 0}$ ppm.

The composite CTO-RGO has been used as a photocatalyst in air purifying device. The prototype of air purifier was tested in an operational environment. Constructed devices were installed in several locations: industrial plant (location 1), 3D printer lab (location 2), apartment (location 3), fitness center (location 4). The most common air pollutants were monitored in each location - before and after device installation. In particular, in location 1 - isobutanol; in location 2 styrene; in location 3 - formaldehyde; in location 4 ethanol (high concentrations of ethanol may be originated by the alcohol base disinfectant distributed in fitness studio). The concentration of air pollutants was monitored once per day. Photocatalytic air purifiers were installed in day " 0 ". Obtained results are shown in Figure 7. In the case of all locations and all pollutants a significant decrease of VOC concentration was noted. However the effects of air purification were different in each location. In apartment, where the number of VOC emitters is low, purification leads to an almost total degradation of formaldehyde. On the other hand in locations where VOC are produced continuously (e.g. location 1 and 2) the photocatalytic filtration leads to a noticeable decrease of VOCs level, but their concentration was still high. This suggests, that probably the total efficiency of purifier is too low. It can be improved by a simple multiplication of filters units or increase of photocatalyst amount.

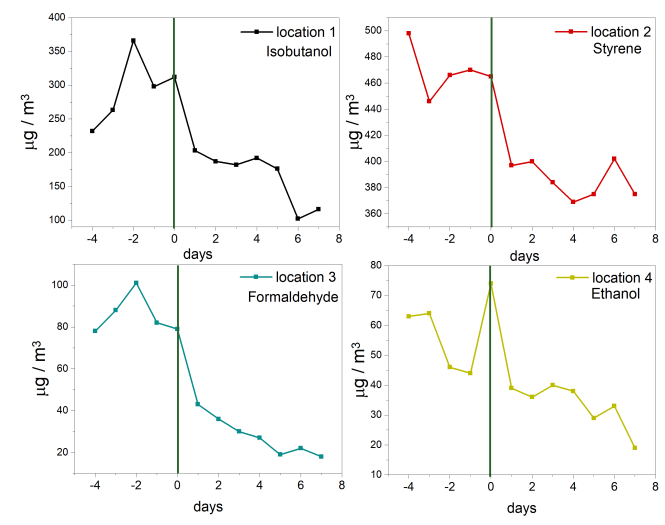

Figure 7: Photocatalytic degradation of VOC in operational environment by using air purifying devices and CTO-RGO composite.

\section{Conclusion}

In this work we described the hydrothermal synthesis of photocatalytic composite CTO-RGO based on copper titanate and reduced graphene oxide. The material is composed of three phases namely rutile, tenorite and reduced graphene oxide, and it shows absorption in a broad range of light (UV and visible light). CTO-RGO showed an excellent photocatalytic activity in a laboratory scale experiment. Therefore it has been used as an active material in air purifying devices. The prototype was tested in operational environments. Obtained results confirmed the significant decrease of VOC level due to photocatalytic degradation of pollutants. Therefore, the air purifying device, after minor modification, can be manufactured as a commercial product.

\section{Acknowledgements:}

This work was co-financed from European Funds from the Regional Operational Program of the Lesser Poland Voivodship for the years 2014-2020 (grant no. RPMP.01.02.01-120407/77-0م)

Cite this article: T. Baran and S. Wojtyła, OAJ

Materials and Devices, Vol 5 \#1, 1203 (2021) - DOI: $10.23647 /$ ca.md20211203

\section{REFERENCES}

[1] I. Manisalidis, E. Stavropoulou, A. Stavropoulos, E. Bezirtzoglou, Front. Public Health 2020, 8, DOI 10.3389/fpubh.2020.00014.

[2] M. Kampa, E. Castanas, Environmental Pollution 2008, 151, 362-367. 
T. Baran and S. Wojtyła, Graphene-titanate photocatalyst and its use in an air purifying device - prototype demonstration

[3] T. Ohura, T. Amagai, X. Shen, S. Li, P. Zhang, L. Zhu, Atmospheric Environment 2009, 43, 6352-6359.

[4] C. Rösch, T. Kohajda, S. Röder, M. von Bergen, U. Schlink, Atmospheric Pollution Research 2014, 5, $129-137$.

[5] S. Wojtyła, P. Klama, K. Śpiewak, T. Baran, Int. J. Environ. Sci. Technol. 2019, DOI 10.1007/s13762-019-02444-X.

[6] S. O. Hay, T. Obee, Z. Luo, T. Jiang, Y. Meng, J. He, S. C. Murphy, S. Suib, Molecules 2015, 20, 1319-1356.

[7] S. Wojtyła, K. Śpiewak, T. Baran, Journal of Photochemistry and Photobiology A: Chemistry 2020, $391,112355$.

[8] Y. Paz, Applied Catalysis B: Environmental 2010, 99, 448-460.

[9] T. Baran, S. Wojtyła, A. Minguzzi, S. Rondinini, A. Vertova, Applied Catalysis B: Environmental 2019, 244, 303-312.

[10] M. Kask, J. Bolobajev, M. Krichevskaya, Chemical Engineering Journal 2020, 399, 125815.

[11] C. Wang, J. Li, G. Mele, G.-M. Yang, F.-X. Zhang, L. Palmisano, G. Vasapollo, Applied Catalysis B: Environmental 2007, 76, 218-226.

[12] S. Cataldo, A. Iannì, V. Loddo, E. Mirenda, L. Palmisano, F. Parrino, D. Piazzese, Separation and Purification Technology 2016, 171, 101-111.

[13] A. Di Paola, G. Cufalo, M. Addamo, M. Bellardita, R. Campostrini, M. Ischia, R. Ceccato, L. Palmisano, Colloids and Surfaces A: Physicochemical and Engineering Aspects 2008, 317, 366-376.

[14] W. Ji, T. Shen, J. Kong, Z. Rui, Y. Tong, Ind. Eng. Chem. Res. 2018, 57, 12766-12773.

[15] T. Baran, S. Wojtyła, A. Vertova, A. Minguzzi, S. Rondinini, Journal of Electroanalytical Chemistry 2018, 808, $395-402$.

[16] W. E. Ghann, H. Kang, J. Uddin, F. A. Chowdhury, S. I. Khondaker, M. Moniruzzaman, M. H. Kabir, M. M. Rahman, ChemEngineering 2019, 3, 7.

[17] B. D. Viezbicke, S. Patel, B. E. Davis, D. P. Birnie, Physica Status Solidi (b) 2015, 252, 1700-1710.

[18] K. Bustos-Ramirez, C. E. Barrera-Diaz, M. De Icaza, A. L. Martínez-Hernández, C. Velasco-Santos, "Photocatalytic Activity in Phenol Removal of Water from Graphite and Graphene Oxides: Effect of Degassing and Chemical Oxidation in the Synthesis Process," 2015. 